Gut, 1971, 12, 891-896

\title{
The gastric secretory response to insulin: an 'all-or-none' phenomenon?
}

\author{
JOHN SPENCER ${ }^{1}$ AND MORTON I. GROSSMAN
}

From the Veterans Administration Center, Los Angeles, California

SUMmaRY Dogs were prepared with Pavlov pouches which could be perfused with saline so as to detect rapidly changes occurring in acid secretion.

Dose-response studies were performed by the intravenous injection of insulin $(0.06,0 \cdot 12,0 \cdot 25,0 \cdot 5$, or $1.0 \mathrm{unit} / \mathrm{kg}$ ). Both the magnitude of peak response and the duration of response were dose-related and both were related to the magnitude of fall in plasma glucose.

These results are not consistent with an 'all-or-none' hypothesis for insulin-stimulated gastric acid secretion, but favour the alternative hypothesis that insulin provides a graded glycopenic stimulus producing a graded secretory response.

It has long been held that the gastric secretory response to insulin hypoglycaemia is an 'all-or-none' phenomenon, initiated when the blood sugar falls below a certain threshold value $(40-50 \mathrm{mg} / 100 \mathrm{ml})$ and giving a peak response whose magnitude is unrelated to the degree of hypoglycaemia. These assumptions have recently been questioned by Baron (1970), who suggested that insulin hypoglycaemia provided a graded glycopenic stimulus producing a graded vagal response. On repeated studies in one human subject Baron found that peak acid output after insulin was significantly correlated with the lowest blood glucose achieved after insulin, or with the fall-or rate of fall of blood glucose. In these studies peak acid output was defined as that in the two consecutive 15-minute samples giving the highest acid output. It is possible, however, that peak acid output in a much shorter period may be the same with all doses of insulin, but that the duration of the secretory response may be greater when hypoglycaemia is prolonged. The 'all-or-none' assumption would in this case be valid, but would appear refuted when long collection periods were used to define acid output. It was to test this hypothesis that the present experiment was carried out. Dogs were prepared with innervated (Pavlov) pouches which were perfused with saline so that changes in acid secretion could be detected rapidly. Dose response studies were then performed to determine the secretory response to insulin.

1Present address, Department of Surgery, Royal Postgraduate Medical School, London, England.

Received for publication 7 June 1971.

\section{Methods}

Two mongrel dogs $(20.4$ and $26.3 \mathrm{~kg})$ were each prepared with a gastric fistula and an innervated fundic pouch (Pavlov). Two Gregory cannulae drained the pouch, at its upper and lower ends (Fig. 1). After a three-week recovery period secretory studies were begun in each dog. These were performed after an overnight fast, during which water but not food was available. The animals stood on tables supported by cloth slings. During each test $154 \mathrm{mM} \mathrm{NaCl}$ was infused into a leg vein at a rate just sufficient to maintain patency in a polyethylene cannula which was used to obtain blood samples. In an initial test histamine dihydro-chloride was infused intravenously at a dose of $0.16 \mathrm{mg} / \mathrm{kg} / \mathrm{hr}$ in order to provide an index of 'maximal' pouch secretion. Pouch secretions were collected as 15minute samples for two hours. Gastric fistula secretion in this and subsequent studies was collected and discarded.

In subsequent studies the pouches were perfused with $154 \mathrm{mM} \mathrm{NaCl}$ at a rate of $1 \mathrm{ml} / \mathrm{min}$, and samples were collected every three minutes (Fig. 1). After a variable initial period (up to 10 minutes) to obtain a steady perfusion, five such three-minute collections were made. Regular insulin (Iletin, Lilly) $(0.06,0.12,0.25,0.5$, or 1.0 unit $/ \mathrm{kg})$ was then injected rapidly intravenously, and collections were continued for a further two hours. No more than one dose was given on each day, and the order of the doses was randomized. One dog received each dose twice, and the second three times. 


\section{PERFUSION OF PAVLOV POUCH}

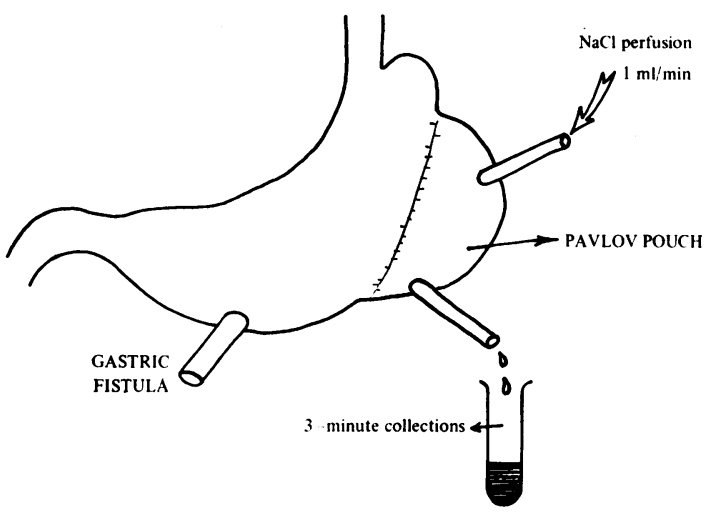

Fig. 1 Method of collection of Pavlov pouch secretion, permitting rapid detection of changes in acid output.
Sample volumes were measured to the nearest $0 \cdot 1$ $\mathrm{ml}$ and titratable acidity to endpoint $p \mathrm{H} 7.0$ was determined with an automatic titrator (Radiometer, Copenhagen, Denmark) using $0 \cdot 2 \mathrm{~N} \mathrm{NaOH}$.

Venous blood was taken before insulin administration and again 10, 20, 30, and $\mathbf{4 0}$ minutes afterwards, and plasma glucose was measured by a glucose oxidase method on an AutoAnalyzer.

\section{Results}

\section{ACID SECRETION}

The maximal one-hour response to histamine-di$\mathrm{HCl}(0.16 \mathrm{mg} / \mathrm{kg} / \mathrm{hr})$ was $3.01 \mathrm{~m}$-equiv $/ \mathrm{hr}$ in $\operatorname{dog} \mathrm{A}$ and $6.01 \mathrm{~m}$-equiv $/ \mathrm{hr}$ in dog B. Higher secretion rates were consistently seen in $\operatorname{dog} B$ in subsequent tests using insulin.

The mean secretory responses to insulin in all the tests are shown in Figure 2. Basal acid output was always very low, and there was no clear inhibition in the early phase following insulin administration. After insulin there was a fairly constant delay of

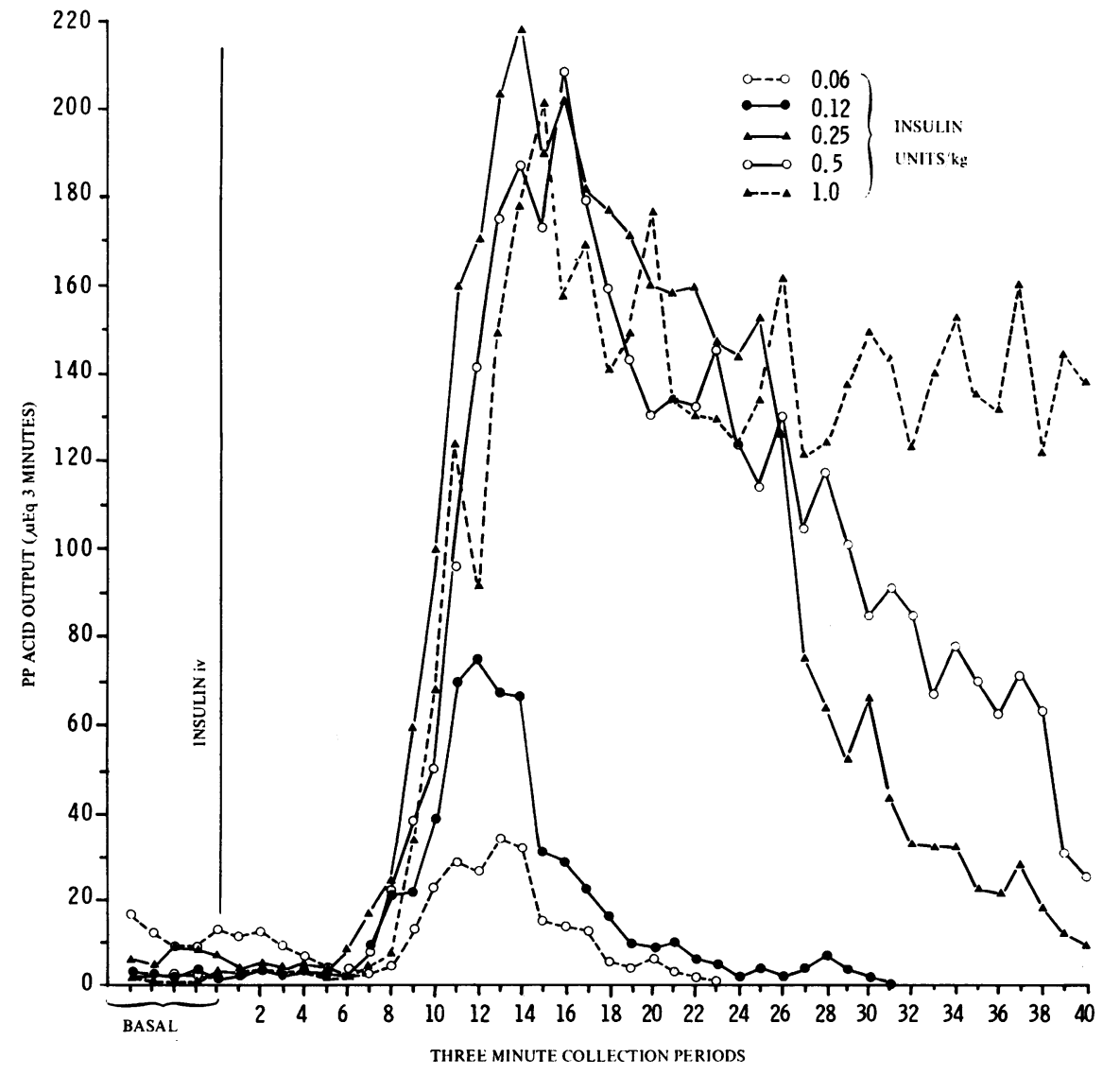

Fig. 2 Acid output from Pavlov pouches in response to insulin; mean results of five tests in two dogs. 


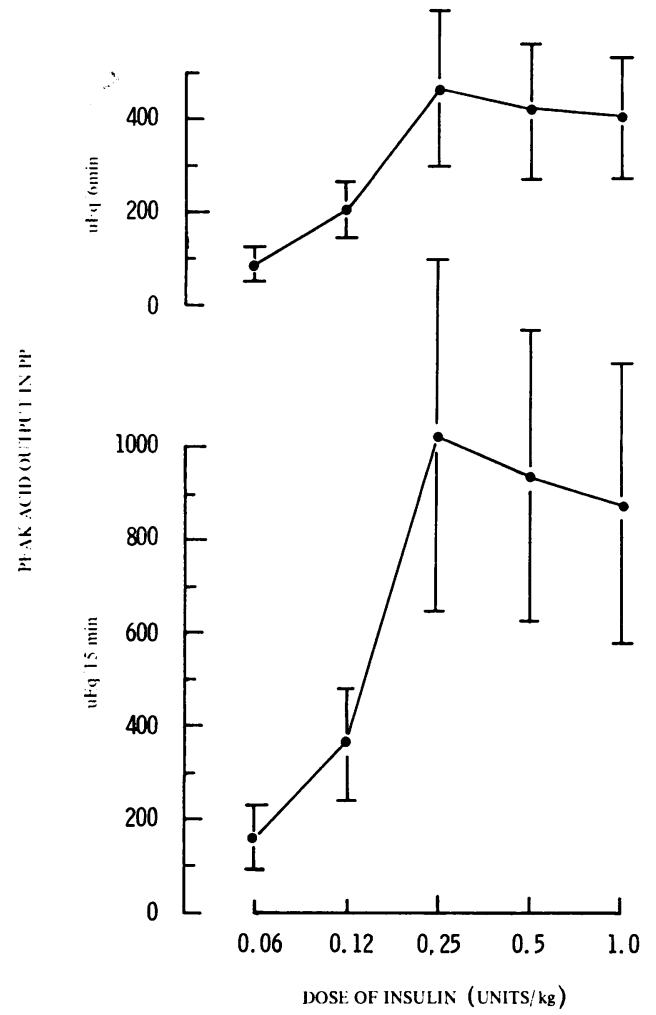

Fig. 3 Peak acid output, expressed in two ways, related to dose of insulin.

15 to 27 minutes before a secretory response occurred. The length of this delay was not related to the dose of insulin. A secretory response followed every dose of insulin used, with the exception that $\operatorname{dog} \mathrm{A}$ did not respond to the 0.06 unit $/ \mathbf{k g}$ dose. The delay between the onset of secretion and peak secretion varied from less than three minutes in two experiments with the 0.12 unit $/ \mathbf{k g}$ dose to 51 minutes in one experiment with the largest dose. With the latter dose (1.0 unit/ $\mathrm{kg}$ ) the timing of the peak was less accurate because of the tendency to a prolonged 'plateau' of secretion. There was a tendency for the onset-to-peak delay to increase with increasing dose, the means for the five graded doses used being $9,6,15,16$, and 31 minutes respectively.

The peak acid output was expressed as the highest output in two consecutive samples (expressed as $\mu$-equiv/6 $\mathrm{min}$ ) or in five consecutive samples ( $\mu$-equiv/15 min), and the results obtained can be seen in Figure 3. Output increased with increasing dose up to 0.25 unit/kg; higher doses did not produce significantly different outputs, nor was there

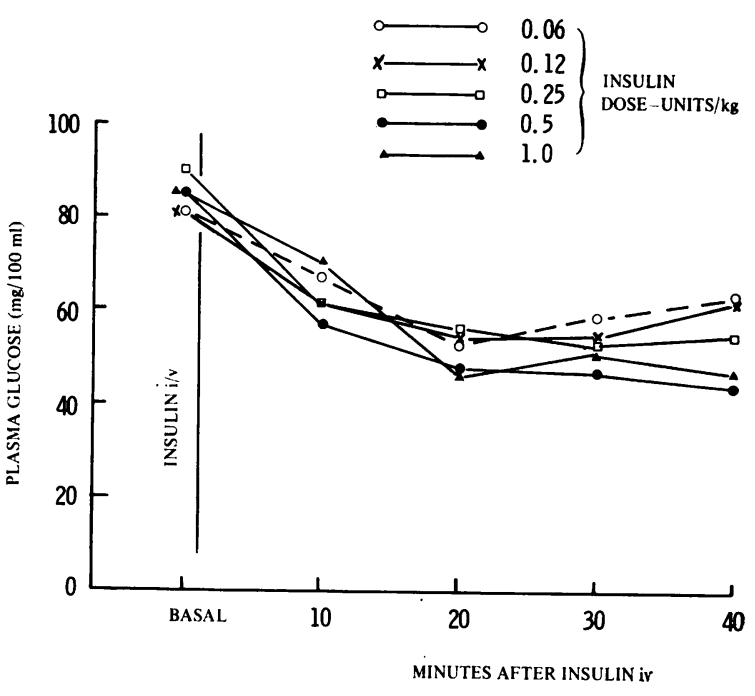

Fig. 4 Changes in plasma glucose after insulin.

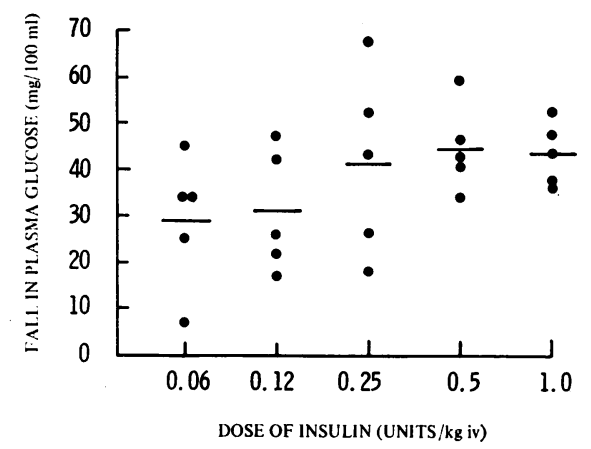

Fig. 5 Absolute fall in plasma glucose related to dose of insulin.

any marked inhibition of secretion with high doses.

The secretory response was more prolonged with higher doses of insulin. With the doses of 0.06 and $0.12 \mathrm{unit} / \mathrm{kg}$ the response had ceased within 30 to 45 minutes of the peak response. With higher doses secretion fell off more gradually, and after the largest dose high rates of secretion were maintained throughout the two-hour collection period.

\section{RELATION TO BLOOD SUGAR CHANGES}

The mean plasma glucose levels are plotted in Figure 4.

It is seen that the time of the lowest plasma glucose corresponds approximately with that of the onset of the gastric secretory response. The fall in 


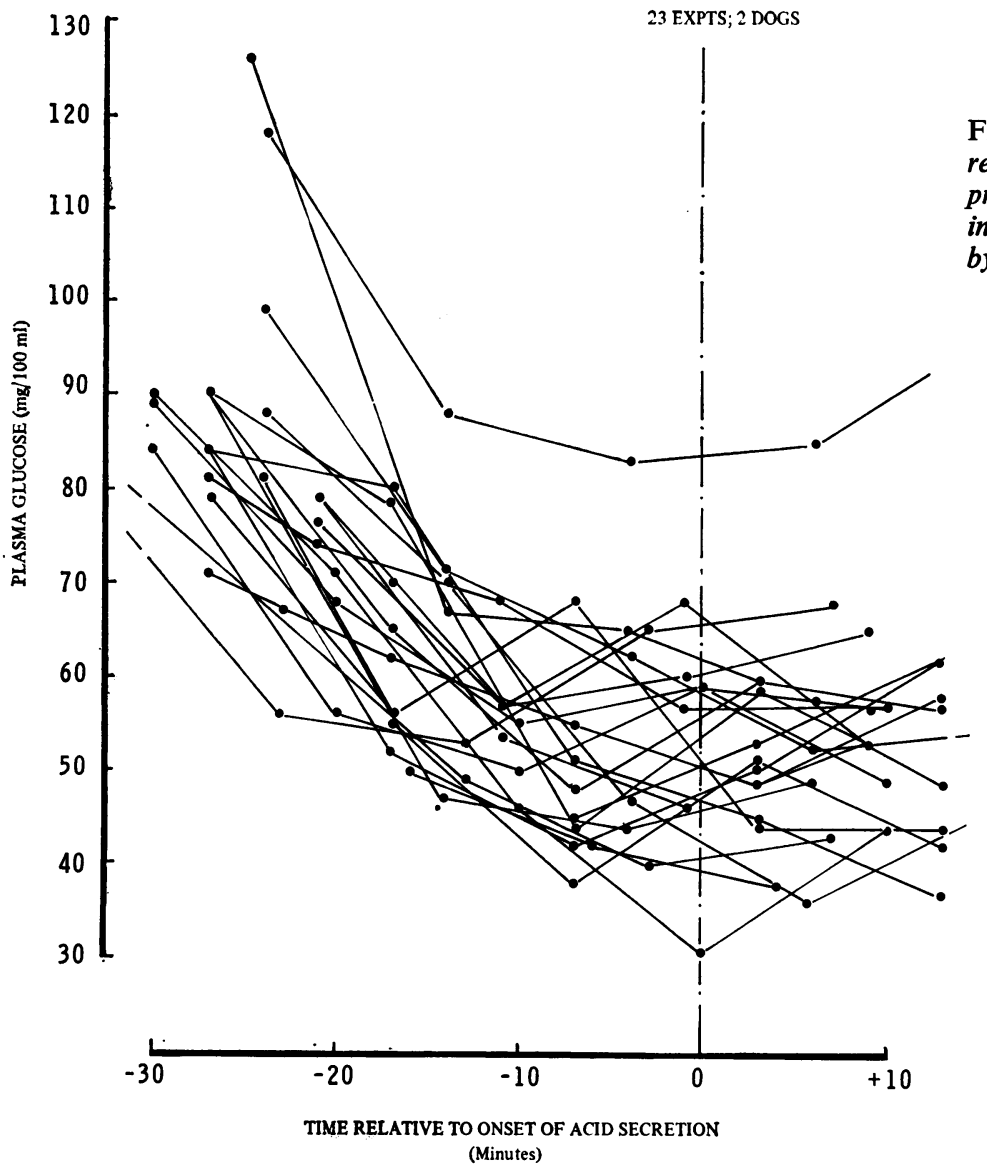

Fig. 6 Changes in plasma glucose related to onset of acid secretion, the precise moment of which was determined in each experiment and is represented by zero on the horizontal axis. plasma glucose tended to be more prolonged after larger doses of insulin, though the slopes of the blood sugar curves were all much the same. As is seen in Fig. 5, the absolute fall in plasma glucose tended to be greater with increasing dose of insulin up to a dose of $0.5 \mathrm{unit} / \mathrm{kg}$, though the differences were small and not statistically significant. Two tests in $\operatorname{dog} \mathrm{A}$ in which no secretory response occurred with $0.06 \mathrm{unit} / \mathrm{kg}$ were associated either with a very small change in blood glucose (a fall of only $6 \mathrm{mg} / 100 \mathrm{ml}$ to $51 \mathrm{mg} / 100 \mathrm{ml}$ in one test) or with a fall to an unusually high nadir (a fall of $25 \mathrm{mg} / 100$ $\mathrm{ml}$ to $65 \mathrm{mg} / 100 \mathrm{ml}$ in the other). The apparent 'threshold' blood glucose at which secretion may have been stimulated was in the region of $60 \mathrm{mg} / 100 \mathrm{ml}$; in one test in which response occurred the lowest recorded blood glucose was $58 \mathrm{mg} / 100 \mathrm{ml}$. By noting when secretion began after insulin, it was possible to relate this in time to the plasma glucose levels obtained during the experiments. By interpolation it was then possible to estimate graphically

\begin{tabular}{|c|c|c|}
\hline $\begin{array}{l}\text { Dose of Insulin } \\
\text { (unit/kg) }\end{array}$ & $\begin{array}{l}\text { Plasma Glucose at } \\
\text { Onset of Secretion } \\
(\mathrm{mg} / 100 \mathrm{ml})\end{array}$ & $\begin{array}{l}\text { Mean and Range } \\
\text { of Plasma Glucose }\end{array}$ \\
\hline 0.6 & $\begin{array}{l}50 \\
59 \\
84 \\
57 \\
66\end{array}$ & $64(50-84)$ \\
\hline $0 \cdot 12$ & $\begin{array}{l}47 \\
51 \\
58 \\
61 \\
67\end{array}$ & $56(47-66)$ \\
\hline 0.25 & $\begin{array}{l}47 \\
41 \\
62 \\
47 \\
59\end{array}$ & $56(41-67)$ \\
\hline 0.5 & $\begin{array}{l}39 \\
46 \\
31 \\
56 \\
54\end{array}$ & $44(31-59)$ \\
\hline $1 \cdot 0$ & $\begin{array}{l}51 \\
42 \\
46\end{array}$ & $50(42-56)$ \\
\hline
\end{tabular}

Table Plasma glucose levels related to insulin dose 


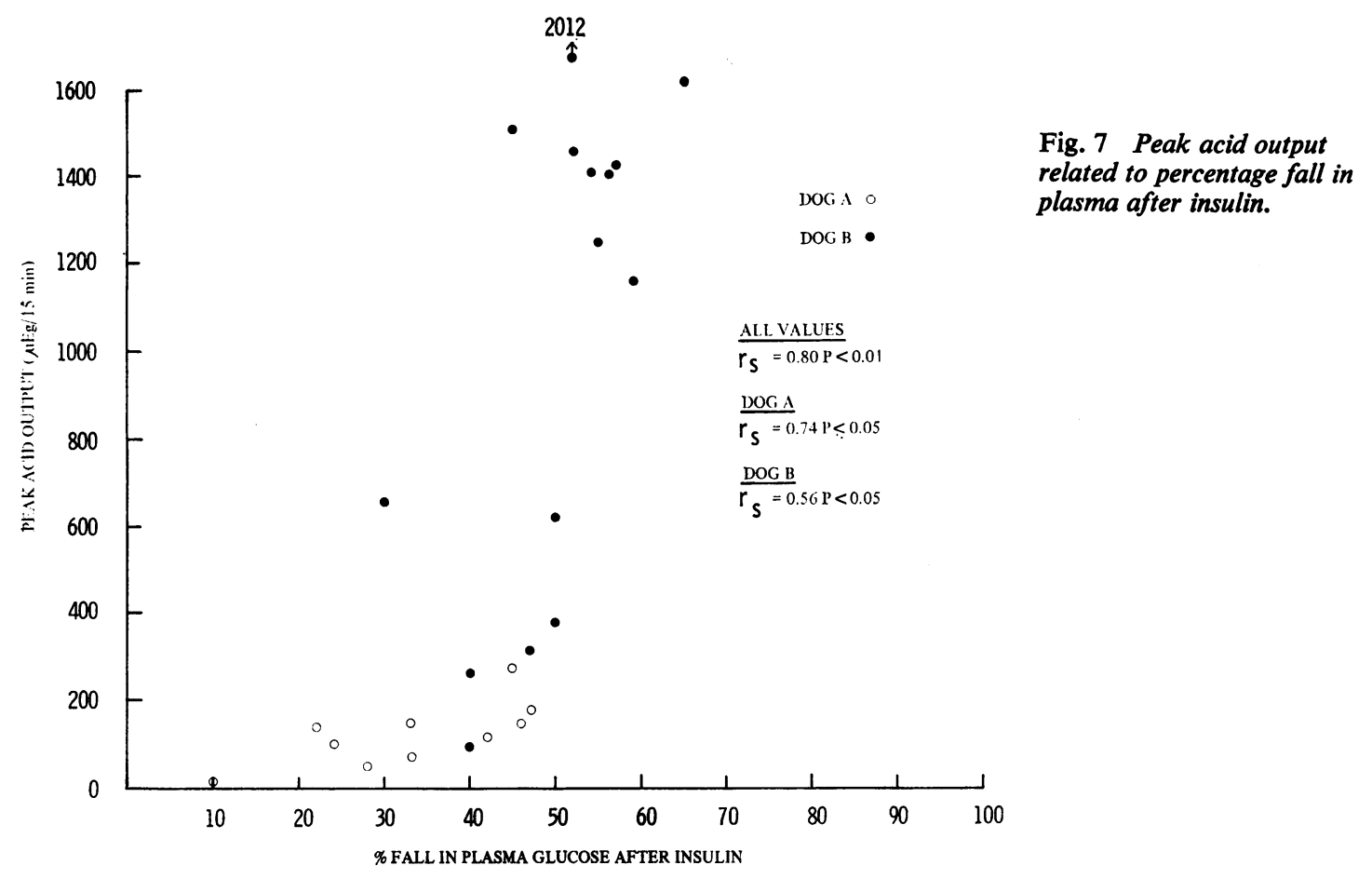

plasma glucose at the time of onset of secretion (Fig. 6; Table). In one test this was $84 \mathrm{mg} / 100 \mathrm{ml}$ : in all others it was in the range of 31 to $67 \mathrm{mg} / 100 \mathrm{ml}$. The plasma glucose level at the time of onset of secretion was independent of the dose of insulin.

The peak acid output, expressed as $\mu$-equiv/15 min, was significantly correlated with the fall in plasma glucose when the latter was expressed as a percentage of the fasting pre-insulin level (Fig. 7). This was the case overall $(P<0.01)$ or if each dog was considered separately ( $P<0.05$ in each).

\section{Discussion}

It has long been assumed that the acid response to insulin hypoglycaemia is an 'all-or-none' phenomenon unrelated to the dose of insulin. This assumption was made as early as 1930 by Roholm and has persisted until very recently. The literature on this subject has been thoroughly reviewed recently by Baron (1970), who pointed out that the 'all-or-none' hypothesis was based on results obtained in series of different individuals. Where individual animals had been examined repeatedly Baron was able to recalculate published data and found significant relationships between acid output and the lowest blood sugar after insulin. In repeated tests in one human subject he refuted the 'all-or-none' hypothesis, finding that peak acid output was significantly correlated with the lowest concentration of blood glucose, the fall in blood glucose, the rate of fall of blood glucose, and the maximum fall of blood glucose in any 15 minutes. Similar graded responses to increasing doses of insulin in man have been reported by Isenberg, Stening, Ward, and Grossman (1969), in the dog by Cooke (1969), and in the cat by Stening and Isenberg (1969).

One technical factor of importance in conducting insulin tests is the length of the period chosen for specimen collections. Most workers have collected 15-minute samples of gastric secretions. If peak response lasted only a few minutes during such prolonged collection periods peak acid output would not be measured accurately. For example, peak responses to all doses of insulin may have been the same, secretion being more prolonged with higher doses. The longer the collection period, the greater the chance that such an event would be overlooked. Conversely the shorter the collection periods, the more possible it becomes to observe the rapid changes in gastric secretion, and assess peak acid output accurately. In man, however, it is technically difficult to make accurate collections of very brief duration. In small animals it is possible to perfuse the whole stomach and thus observe very promptly the changes which occur in acid secretion. Colin- 
Jones and Himsworth (1969) have described the use of such a preparation in experiments in rats in which 3-0-methylglucose (a non-metabolizable hexose) was used to promote acid secretion by vagal stimulation. They concluded that the response was not graduated to the severity of the hypoglycaemia but was 'on-off' in character but they did not present data to support this view.

In the present study dogs were used, and by perfusing Pavlov pouches with saline it was possible to monitor secretion accurately and rapidly. No inhibition of gastric secretion was seen in the early phase following insulin injection. Such inhibition has often been described in man (Mahler, 1930; Roholm, 1930; Olson and Necheles, 1953 and 1955) but it is possible that this was due to contamination of early commercial insulins with glucagon (Aylett, 1962). Using Boots insulin, which has a negligible concentration of glucagon, Baron (1970) was unable to detect inhibition in the early presecretory phase. The insulin used in the present studies (Iletin, Lilly) contains a very small glucagon concentration $(0 \cdot 1 \%)$.

The secretory response is believed to be initiated when a certain threshold blood glucose level is reached during the fall in concentration after insulin. The limited data available in the present study do not allow a precise determination of this threshold, but are consistent with it being in the region of 60 $\mathrm{mg} / 100 \mathrm{ml}$, which is well within the usually quoted range (Stempien, Lee, and Dagradi, 1968). The existence of such a threshold is beyond doubt, and in this sense secretion is 'on-off' in character, as described by Colin-Jones and Himsworth (1969). It is important, however, to distinguish between an absolute threshold for initiation of stimulation, and the question of whether hypoglycaemia greater than threshold (in strength and duration) produces only prolongation of response or produces graded responses in terms of peak rates attained. The present studies in the dog, in which peak acid output could be measured more precisely than in human studies, confirm the contention of Baron (1970) that insulin provided a graded glycopenic stimulus producing a graded acid response. Peak acid output was directly related to the fall in blood sugar produced by insulin. There was also a curious delay in achieving peak secretion with increasing dose of insulin; we are unable to explain this finding.

The authors are indebted to Mr John Washington and Mr Ray Lichter for expert technical assistance. J.S. was in receipt of a Wellcome travel grant.

\section{References}

Aylett, P. (1962). The effects of glucagon and glucagon-free insulin upon gastric secretion in peptic ulcer patients. Clin. Sci., 22 179-184.

Baron, J. H. (1970). Dose response relationships of insulin hypoglycaemia and gastric acid in man. Gut, 11, 826-836.

Colin-Jones, D. G., and Himsworth, R. L. (1969). The secretion of gastric acid in response to a lack of metabolizable glucose. J. Physiol. (Lond.), 202, 97-109.

Cooke, A. R. (1969). Acid and pepsin secretion in response to endogenous and exogenous cholinergic stimulation and pentapeptide. Aust. J. exp. Biol. med. Sci., 47, 197-202.

Isenberg, J. I., Stening, G. F., Ward, S., and Grossman, M. I. (1969). Relation of gastric secretory response in man to dose of insulin. Gastroenterology, 57, 395-398.

Mahler, P. (1930). Beiträge zur Chemie des Menschlichen Magensaftes. Wien. Arch. inn. Med., 19, 413-450.

Olson, W. H., and Necheles, H. (1953). Initial depression of human gastric secretion by insulin. Gastroenterology, 24, 362-368.

Olson, W. H., and Necheles, H. (1955). Primary depression of gastric secretion by insulin in normal man. J. Amer. med. Ass., 159, 1013-1014.

Roholm, K. (1930). Clinical investigations into the effect of intravenous injection of insulin. IV. Gastric secretion in norma individuals. Acta med. scand., 73, 472-492.

Stempien, S. J., Lee, E. R., and Dagradi, A. E. (1968). Clinical appraisal of insulin gastric analysis. Amer. J. dig. Dis., 13, 21 34

Stening, G. F., and Isenberg, J. I. (1969). Insulin-induced acid secretion, after partial vagotomy in dogs and cats. Amer. J. Physiol., 217, 962-964. 